This paper is published as:

Druckman, A., P. Bradley, E. Papathanasopoulou and T. Jackson (2008). "Measuring progress towards carbon reduction in the UK " Ecological Economics 66(4): 594-604.

\title{
Measuring Progress towards Carbon Reduction in the UK
}

\author{
A Druckman, P Bradley, E Papathanasopoulou and T Jackson
}

ESRC Research Group on Lifestyles, Values and Environment (RESOLVE)

University of Surrey, Guildford GU2 7XH, UK

Correspondence address:

Angela Druckman

Centre for Environmental Strategy

University of Surrey

Guildford GU2 7XH

UK

Tel: $+44(0) 1483686679$

Fax: $+44(0) 1483876671$

Email: a.druckman@surrey.ac.uk

\begin{abstract}
The UK Climate Change Bill proposes to establish legally binding targets for a $60 \%$ reduction in carbon dioxide emissions by 2050 . This paper discusses the challenges posed by measuring progress towards this target. It takes as a premise that the conventional productionbased accounting framework, enshrined in the UNFCCC emissions accounting guidelines, is inappropriate for this task because it fails to account for the carbon 'traded' across the UK national boundary. Accordingly, it sets out a consumption-based accounting framework using a two-region Environmental Input-Output (EIO) model - which could in principle measure progress in reducing the emissions attributable to final consumers in the UK. It illustrates the use of this framework to measure the reduction in carbon dioxide achieved by the UK between 1990 (the Kyoto base year) and the year 2004 and compares this against the production perspective. The results indicate that any progress towards the UK's carbon reduction targets (visible under a production perspective) disappears completely when viewed from a consumption perspective. But the robustness of this conclusion depends critically on the accuracy of underlying economic and environmental data sets as well as specific assumptions concerning imports. By analysing the consistency of UK Input Output data, we conclude that EIO is still some way from being able to answer the critical question of the carbon trade balance for the UK. In these circumstances, measuring real progress towards carbon reduction in the UK remains elusive.
\end{abstract}

Keywords: Input-output analysis; Carbon dioxide emissions; Energy policy; Carbon trade balance. 


\section{Introduction}

The ultimate aim of the analysis in this paper is to answer one simple question: what real progress is being made in reducing the carbon footprint of UK lifestyles?

With an increasing awareness of the gravity of climate change, the UK government has recently launched its consultation on a new Climate Change Bill which sets legally binding targets for a $60 \%$ reduction in carbon dioxide emissions by 2050 and a $26-32 \%$ reduction by 2020 compared to 1990 levels (HM Government 2007). Such targets would be the first of their kind in the world (ENDS 2007). These proposed domestic targets will be in addition to the Kyoto Treaty target (according to which the UK is to reduce greenhouse gas (GHG) emissions by $12.5 \%$ below 1990 levels by 2008-2012) and the Labour Party's domestic goal to cut carbon dioxide emissions by $20 \%$ by 2010 - a goal which, the Government has now admitted, is unlikely to be achieved.

Measuring progress towards any of these targets has conventionally followed the UNFCCC GHG emission reporting guidelines. Under these guidelines accounting is carried out from the so-called 'production-based' perspective (United Nations 2004). Using this perspective emissions associated with exports are included but those associated with imports are excluded from the national account. Upstream resources used in the production of goods are attributed to the producer, not the consumer of those goods. The difficulty with this approach is that it tends to mask the problem of 'burden shifting' - in which energy intensive industries are 'exported' to other (often less developed) countries while consumption of final products continues to rise by relying increasingly on the import of finished or semi-finished products (Machado et al. 2001; Ahmad and Wyckoff 2003; Papathanasopoulou and Jackson 2007).

To overcome this difficulty, it has been widely argued that the correct approach to measuring progress in reducing greenhouse gas emissions is to use a consumption-based perspective, which accounts for all of the emissions attributable to the consumption activities of the nation (Munksgaard and Pedersen 2001; Bastianoni et al. 2004; Peters and Hertwich 2006). In the consumption perspective exports are excluded and imports are included. In this way, the upstream resources associated with both domestic and imported goods are allocated to final consumption in the nation being measured.

The difference between the production perspective and the consumption perspective is known as the 'carbon trade balance'. A positive carbon trade balance confirms the hypothesis that a country's consumption patterns are creating a 'pollution haven' effect abroad; in other words that the country is 'exporting' energy-intensive industries and importing the semi-finished or finished consumer products demanded by UK lifestyles. A negative carbon trade balance would indicate that in fact there is more carbon associated with the UK's production activities than with its consumption activities and, in effect, the UK is operating as a 'pollution haven' for the consumption activities of others.

Current climate policies follow the production perspective. This is a pragmatic approach that has two major advantages. First, as we will show in this paper, accounting from the production perspective is relatively straightforward. Second, governments are able to apply effective regulatory and fiscal policies to limit emissions from operations within their own territories, whereas applying such measures to imported goods is problematic. The success of production based policies can be judged from the relatively lower carbon intensities of production processes in developed countries in contrast to those in less developed countries (Ahmad and Wyckoff 2003; Nijdam et al. 2005; Peters and Hertwich 2006). The drawback of 
pursuing purely production based policies is demonstrated by the positive (and growing) carbon trade balance of most developed countries.

A potential shift in policy from production based policies towards consumption based policies is perhaps heralded by a recommendation by the Dutch government that sustainable economic growth should avoid developments that increase the positive carbon trade balance of the Netherlands (Wilting and Vringer 2007). There are, however, many obstacles to effective implementation of policies from the consumption perspective. The first is the challenge of accounting from the consumption perspective which is the subject of this paper. Second, there is a natural tendency by producers operating in competitive markets under World Trade Organisation rules to transfer production to developing countries where environmental policies tend to be more benign (Munksgaard and Pedersen 2001; Wilting and Vringer 2007). Therefore, pragmatically, consumption based policies can currently only be implemented on a voluntary basis through, for example, supply chain management and consumer pressure. The consumption perspective is, however, arguably more egalitarian (Bastianoni et al. 2004) and is considered by many to be the appropriate method for assessing the emissions for which each nation must take responsibility.

The starting point of this paper is therefore to accept that progress in reducing the UK's carbon footprint should be measured using the consumption perspective. Our principal aim is to compare and contrast the results of the production-based and consumption-based accounts of UK emissions for two snapshot years: 1990 (the base year for Kyoto targets) and 2004 (the most recent year for which key economic data can be found). In this way it ought, in principle, to be possible to answer the question of real progress towards carbon reduction targets.

In Section 2 of the paper we set out in some detail a basis for the consumption based accounting framework which uses Environmental Input-Output (EIO) analysis. In the course of this exercise however, we have been drawn inevitably to examine the two major sources of uncertainties. The first is uncertainty due to the assumption that imported goods have the same carbon footprint as those produced domestically. This uncertainty can be addressed by developing a multi-regional input-output model (Peters and Hertwich 2006; Weber and Matthews 2007; Wiedmann et al. 2007). Development of a multi-regional input-output model is beyond the scope of this paper, although its importance is illustrated by a sensitivity analysis. The focus of this paper is investigation of uncertainties due to the (un-)reliability of the underlying data sets for the UK. Section 3 discusses how and where these issues concerning UK data have arisen, and outlines the methodological choices faced in overcoming certain data limitations. Section 4 presents the results of using the best publicly available data (under a certain set of assumptions) to calculate both production and consumption based accounts of carbon dioxide emissions in 1990 and 2004. In Section 5, we discuss the robustness of these results by examining the consistency of certain basic underlying UK data sets. We also discuss how consistency in these data compare across different countries. Finally, we explore the implications of our findings for UK policy.

\section{Developing a Consumption-based Framework}

Measuring progress in reducing carbon dioxide emissions (on either the production or the consumption perspective) relies on the compilation of national emissions inventories. It is now recognised that these inventories already have high uncertainties, and in some cases the margins of uncertainty are of a similar magnitude to the change that we are attempting to 
measure. For example, the reported uncertainty in total GHG emissions has been found to range from $\pm 5 \%$ to $\pm 20 \%$ for five industrialised countries with reputedly high standard GHG inventories; and, for the UK, uncertainties range from $\pm 4 \%$ for carbon dioxide to $\pm 200 \%$ for nitrogen dioxide (Rypdal and Winiwarter 2001).

These uncertainties are compounded in the consumption-based perspective by issues related to basic underlying economic data sets required for EIO. Specifically, EIO is an economywide, top-down approach that draws on national economic accounting frameworks to map the structural components of direct and indirect resource demand, and to attribute resource usage to final demand (Miller and Blair 1985; Leontief 1986; Tukker and Jansen 2006; Wiedmann et al. 2006). The core of EIO is a matrix that describes flows through the economy, showing the sales and purchases between industrial sectors and/or product sectors. In theory, all interindustry transactions to an infinite order are modelled, providing a method of obtaining information on all upstream energy flows (Lenzen 2001; Femia and Moll 2005). This makes EIO a unique tool, as it reveals the impact that ripples through all industrial sectors from a change in final demand.

EIO relies on the publication of specific datasets and the European System of Accounts ESA 95 has established a compulsory regime for European Member States to produce these data (European Commission 2007) ${ }^{1}$. The obligation covers annual supply- and use-tables on the one hand, five-yearly symmetric input-output tables, symmetric input-output tables of domestic production and symmetric input-output tables of imports on the other. However, it is now well known amongst specialist input-output circles that, despite the EU obligation, the UK lacks the up-to-date datasets which are fundamental to EIO. A part of our aim in this paper is to review the published UK datasets and assess their adequacy as a basis for measuring progress towards carbon reduction targets. By selecting the most transparent and robust methodology available based on published datasets, we estimate changes in carbon dioxide emissions from a consumption perspective between 1990 and 2004, and assess what this means both from the point of view of progress towards the emissions reduction targets, and with regards to the evidence base on which UK sustainable consumption must rest.

In order to differentiate between carbon emissions ${ }^{2}$ generated at home and those generated abroad to meet UK consumer demand, we use a two region Environmental Input-Output (EIO) model based on work by Proops et al (1993) and developed further by the University of Surrey (Carbon Trust 2006; Jackson et al. 2006). The two regions are the UK and the Rest of the World (ROW). The model is illustrated in Figure 1. Each region is shown to have a production sector and consumption sector. The UK production sector supplies UK consumption (arrow P), the Rest of the World consumption (T), and it also supplies intermediate products and services to Rest of the World production (S). UK consumption is supplied by imported goods and services $(\mathrm{R})$ and UK production $(\mathrm{P})$, some of which is made from imported intermediate goods and services $(\mathrm{Q})$.

In summary therefore, we denote by:

$\mathrm{C}_{\mathrm{P}}-$ the carbon associated with the flow $\mathrm{P}$ of goods produced in the UK to meet final demand in the UK;

\footnotetext{
${ }^{1}$ This obligation became valid as of end 2002, and covers the period from 1995 onwards.

${ }^{2}$ In this study 'carbon emissions' refer to carbon dioxide emissions from energy use, measured in $\mathrm{mtC}$.
} 
$\mathrm{C}_{\mathrm{Q}}$ - the carbon associated with the flow $\mathrm{Q}$ of goods produced in the Rest of the World to meet intermediate demand in the UK for goods destined for final demand in the UK; ${ }^{3}$

$\mathrm{C}_{\mathrm{R}}-$ the carbon associated with the flow $\mathrm{R}$ of goods produced in the Rest of the World to meet UK final demand;

$\mathrm{C}_{\mathrm{S}}$ - the carbon associated with the flow $\mathrm{S}$ of goods produced in the UK to meet intermediate demand in the Rest of the World; ${ }^{4}$ and by

$\mathrm{C}_{\mathrm{T}}$ - the carbon associated with the flow $\mathrm{T}$ of goods produced in the UK to meet final demand in the Rest of the World;

We can express the carbon, $\mathrm{C}_{\text {tot }}^{\text {prod }}$, associated with the UK from a production perspective as:

$$
\mathrm{C}_{\text {Tot }}^{\text {Prod }}=\mathrm{C}_{\mathrm{P}}+\mathrm{C}_{\mathrm{S}}+\mathrm{C}_{\mathrm{T}}+\mathrm{C}_{\text {dom }}+\mathrm{C}_{\text {trans }}
$$

while the carbon $\mathrm{C}_{\text {tot }}^{\text {cons }}$ associated with the $\mathrm{UK}$ from a consumption perspective is given by:

$$
\mathrm{C}_{\mathrm{Tot}}^{\text {Cons }}=\mathrm{C}_{\mathrm{P}}+\mathrm{C}_{\mathrm{Q}}+\mathrm{C}_{\mathrm{R}}+\mathrm{C}_{\mathrm{dom}}+\mathrm{C}_{\text {trans }}
$$

where:

$\mathrm{C}_{\mathrm{dom}}$ is the carbon associated with household direct consumption of fossil fuels (for heating and cooking and so on in peoples' homes);

$\mathrm{C}_{\text {trans }}$ is the carbon associated with direct consumption of transport fuels by private households.

For the purposes of this paper, calculation of carbon emissions from the production perspective is relatively straightforward, drawing directly on emissions inventory data published by the Office for National Statistics (ONS) in the UK Environmental Accounts (Office for National Statistics 2006) and the Digest of UK Energy Statistics (Department of Trade and Industry 2006). In order to estimate carbon emissions from the consumption perspective we use Environmental Input-Output Analysis (EIO). EIO methodology relies on a number of assumptions which are extensively covered in the standard literature and therefore not repeated here (see for example, Miller and Blair (1985) and Leontief (1986)).We explain EIO here first with reference to a single region, whose industries' total outputs (x) supply all the goods and services required to meet the region's final demand $(\mathbf{y})$. Broadly speaking, the vector of industry output, $\mathbf{x}$, is related to the vector of final demand, $\mathbf{y}$, using the conventional input-output equation:

$$
\mathbf{x}=(\mathbf{I}-\mathbf{A})^{-1} \mathbf{y}
$$

where:

I is the identity matrix;

A is the matrix of technology coefficients (often referred to as the A-Matrix);

$(\mathbf{I}-\mathbf{A})^{-1}$ is the Leontief inverse matrix.

$\mathbf{x}$ is a vector of industry total output;

$\mathbf{y}$ is a vector of final demand.

To apply this equation to environmental modelling of carbon emissions for EIO, we premultiply both sides of the equation by the vector of carbon intensity coefficients, $\mathbf{u}$. This is

\footnotetext{
3 Note that for accounting purposes this flow must exclude the goods required to produce the demand for exports back to the Rest of the World.

4 Note that, in principle, some of the carbon $\mathrm{C}_{\mathrm{S}}$ may support intermediate processes used in the Rest of the World to produce goods destined for intermediate or final demand in the UK. This carbon is usually ignored in the literature on the basis of the relative size of the UK by comparison with the Rest of the World - an assumption known as the small country assumption (Proops et al 1993).
} 
the quantity of carbon emissions per unit monetary output for each industry sector $i$, and is calculated according to:

$$
u_{i}=\frac{\sum_{n=1}^{n=m} f_{n} c_{n}}{x_{i}}
$$

where:

$f_{n}$ is the quantity of fuel type $n$ used in sector $i \quad(n=1$ to $m)$

$c_{n}$ is the carbon emission factor for fuel type $n$

$x_{i}$ is the output of sector $i$

In vector notation, the total carbon $\mathrm{C}$ associated with all production sectors across the economy (including the public sector) is given by:

$$
\mathrm{C}=\sum_{\mathrm{i}} \mathrm{c}_{\mathrm{i}}=\mathbf{u}^{\prime} \mathbf{x}
$$

In this study particular attention is paid to modelling carbon associated with the electricity production and distribution sector. In order to take account of the different losses and tariffs in supplying industry and domestic final demand, the carbon intensity coefficient for this sector is modified to represent supply to industry. Energy due to direct domestic energy use is then taken from the Digest of United Kingdom Energy Statistics (Department of Trade and Industry 2006).

Substitution for $\mathbf{x}$ in equation 5 using equation 3 yields the equation that lies at the heart of Environmental Input-Output (EIO), and this equation gives the carbon attributable to final consumption:

$$
\mathrm{C}=\mathbf{u}^{\prime}(\mathbf{I}-\mathbf{A})^{-1} \mathbf{y}
$$

In order to make the distinction between goods and services that are supplied from overseas and those that are supplied by UK industry, we now apply the two-region model, illustrated in Figure 1. For the consumption perspective, we need to derive explicit expressions for each of the components denoted by arrows $\mathrm{P}, \mathrm{Q}$ and $\mathrm{R}$ in the EIO framework. The derivation is beyond the scope of the present paper. However, details can be found in Proops et al (1993) and (Jackson et al. 2007). It turns out that, after making the small country assumption (see footnote 4) the following identities hold:

$$
\begin{gathered}
\mathrm{C}_{\mathrm{P}}=\mathbf{u}^{\mathbf{1}^{\prime}}\left(\mathbf{I}-\mathbf{A}_{1}\right)^{-1} \mathbf{y}^{\mathbf{1 1}} \\
\mathrm{C}_{\mathrm{Q}}=\mathbf{u}^{\mathbf{2}^{\prime}}\left(\mathbf{I}-\mathbf{A}_{2}\right)^{-1} \mathbf{B}_{21}\left(\mathbf{I}-\mathbf{A}_{1}\right)^{-1} \mathbf{y}^{\mathbf{1 1}} \\
\mathrm{C}_{\mathrm{R}}=\mathbf{u}^{2^{\prime}}\left(\mathbf{I}-\mathbf{A}_{2}\right)^{-1} \mathbf{y}^{\mathbf{2 1}}
\end{gathered}
$$

where:

$\mathbf{A}_{\alpha}$ is the matrix of intra-regional technical coefficients for region $\alpha$;

$\mathbf{B}_{\alpha \beta}$ is the imports use coefficients matrix for imports from region $\alpha$ to region $\beta$. This is often referred to as the Imports Use Matrix

$\mathbf{u}^{\boldsymbol{\alpha}}$ is the vector of carbon coefficients for region $\alpha$; and

$\mathbf{y}^{\boldsymbol{\beta} \boldsymbol{\alpha}}$ is the vector of final demand for commodities produced in region $\beta$ and consumed in region $\alpha$.

In order to simplify the data requirements, we also make the assumption that imported goods have the same carbon footprint as those produced domestically (the 'domestic technology assumption'). In other words, we assume the following condition holds: 


$$
\mathbf{u}^{1^{\prime}}\left(\mathbf{I}-\mathbf{A}_{1}\right)^{-1}=\mathbf{u}^{2^{\prime}}\left(\mathbf{I}-\mathbf{A}_{2}\right)^{-1}
$$

This equation then allows us to express equations (8) and (9) as:

$$
\begin{gathered}
\mathrm{C}_{\mathrm{Q}}=\mathbf{u}^{\mathbf{1}^{\prime}}\left(\mathbf{I}-\mathbf{A}_{1}\right)^{-1} \mathbf{B}_{21}\left(\mathbf{I}-\mathbf{A}_{1}\right)^{-1} \mathbf{y}^{\mathbf{1 1}} \\
\mathrm{C}_{\mathrm{R}}=\mathbf{u}^{\mathbf{1}^{\prime}}\left(\mathbf{I}-\mathbf{A}_{1}\right)^{-1} \mathbf{y}^{\mathbf{2 1}}
\end{gathered}
$$

This carbon attribution framework enables us to estimate carbon emissions generated by each sector of industry due to each of the different elements of final demand: households (including Not for Profit Institutions Serving Households (NPISH)), government, and investment (including fixed capital investment, changes in stocks, and valuables (Office for National Statistics 2003). It also enables us to estimate carbon attributable to functional uses. Reporting on functional uses is beyond the scope of the current paper, but examples can be seen in Carbon Trust (2006) and Jackson et al (2006).

The domestic technology assumption is not altogether satisfactory as it assumes that the economic structure and energy mix in the Rest of the World can be approximated by those in the UK. This may be true for some importing regions but, in particular, it underestimates the carbon associated with imports from developing countries where more energy intensive processes often dominate the economic structure (Peters and Hertwich 2006; Wilting and Vringer 2007). An increasingly used technique for overcoming the drawbacks of the domestic technology assumption is multi-regional input-output modelling (Peters and Hertwich 2006; Weber and Matthews 2007; Wiedmann et al. 2007). As the purpose of this paper is to investigate the reliability of UK datasets, the implication of this assumption is simply illustrated here by carrying out a sensitivity analysis in which the carbon footprint of goods imported from non-OECD countries is assumed to be double that of domestically produced goods ${ }^{5}$, while imports from OECD countries are assumed to have the same carbon footprint as those produced in the UK. In other words, for imports from non-OECD countries:

$$
\mathbf{u}^{2^{\prime}}\left(\mathbf{I}-\mathbf{A}_{2}\right)^{-1}=2\left(\mathbf{u}^{\mathbf{1}^{\prime}}\left(\mathbf{I}-\mathbf{A}_{1}\right)^{-1}\right)
$$

\section{Data requirements for two-region ElO modelling}

In this section we consider the data requirements for modelling UK carbon emissions from the consumption perspective using EIO. As stated in the Introduction, the UK lacks up-todate monetary datasets. Table 1 presents a comparison between monetary data requirements against data published by the UK authorised statistics body, the Office for National Statistics (ONS). Monetary data available for Scotland ${ }^{6}$, which is part of the UK, is also shown, as is the data available for Finland from Statistics Finland ${ }^{7}$.

The data for Scotland and Finland are included in order to compare the availability of monetary data for different countries. It should be noted that in this section we are considering monetary data requirements only, as energy use by industry $\left(\mathbf{f}_{n}\right)$ is available on an annual basis for the UK from the Environmental Accounts and at an aggregated level from

\footnotetext{
${ }^{5}$ Information concerning the origin of imports to the UK is obtained from Office for National Statistics (2007); carbon intensity of GDP in China (for example) is $0.66 \mathrm{tCO} 2 / \$ \mathrm{k}$ at purchasing power parity (PPP), about double that in the UK (International Energy Agency 2006).

${ }^{6}$ Available from http://www.scotland.gov.uk/Topics/Statistics/14713/484

${ }^{7}$ Available from

http://pxweb2.stat.fi/database/National\%20accounts/National\%20accounts/National\%20accounts/Inputoutput/Input-output.asp.
} 
the Digest of UK Energy Statistics (Department of Trade and Industry 2006), and therefore does not present a problem.

Table 1 illustrates that for the UK, for the years 1990 and 1995, we have all the data required to run the EIO model (as presented in equations 7, 11 and 12) at both the 123 sector and the 138 sector level. However, for later years, the required data are not published in the UK. Data availability for Scotland is better, with Leontief Inverse Matrices and domestic supplied final demand in basic prices available annually from 1998 to 2003. This is interesting as data for Scotland are derived partly from UK data supplied by the UK ONS to the Scottish Executive (Croasdale 2006). This situation demonstrates that, given political will, the data required for EIO can be produced. Suitable data concerning imports are not, however, published for Scotland $^{8}$. Data availability for Finland is superior to that for either the UK or Scotland; complete monetary datasets are published annually by Statistics Finland on which to base EIO.

In the following subsections we consider the problems posed by attempting to adapt UK published data to meet our needs. In particular, monetary values must be in a consistent price basis. We will consider the data requirements for years after 1995 in two sections: first, derivation of disaggregated final demand in basic prices, and second, consideration of a suitable Leontief Inverse Matrix.

\subsection{Disaggregated Final Demand in Basic Prices}

The ONS publishes combined (import and domestic supplied) final demand in purchasers' prices annually. Two steps are necessary to calculate disaggregated final demand $\left(\mathbf{y}^{\mathbf{1 1}}\right.$ and $\left.\mathbf{y}^{\mathbf{2 1}}\right)$ in basic prices for years after 1995 from the published data: first values must be converted from purchasers' to basic prices, and second, import and domestic supplied final demand must be separated from combined final demand (Office for National Statistics 2002). We next consider these steps in turn.

Basic prices are the prices at which an industrial seller completes transactions, whereas purchasers' prices are valued at the point of purchase by consumers (Miller and Blair 1985; Lenzen et al. 2004; Mahajan 2007). To move from purchasers' prices to basic prices it is necessary to remove distributors' margins from intermediate and final demand of goods and add them to wholesale and retail distribution sectors, and subtract taxes less subsidies on products and the imports of goods and services (Office for National Statistics 2002). Annual data on taxes less subsidies on products, and distributors' margins are supplied in the Supply Table. However, the values apply to all elements of final demand as well as to intermediate demand, and we must somehow allocate them between intermediate demand by each industry sector and the elements of final demand. This allocation is problematic in the absence of further data being released by the ONS. One possible way is to assume that distributors' margins, taxes and subsidies apply in the same proportion in year 2004 as they did in 1995, for all elements of demand (combined intermediate demand and combined final demand). We are able to find these proportions from published 1995 data and apply them to 2004 data. An alternative method would be to assume that distributors' margins and taxes less subsidies are applied pro-rata across all industries' intermediate demand and final demand. Both these methodologies are fully transparent and based on published accredited data, but give different

\footnotetext{
However McGregor et al have made use of unpublished experimental data made available to them by the input-output team at the Scottish Executive to estimate Scottish imports from the rest of the UK (McGregor et al. 2004).
} 
results. In this study we use the first of the methods described above. This has been chosen because the pro-rata approach does not reflect differential distribution margins, taxation rates and subsidies across sectors. This is important because some sectors, such as tobacco products and alcoholic beverages, are taxed heavily, whereas others, such as agriculture, receive subsidies. In theory, it is possible to apply more sophisticated methodology to give enhanced accuracy. However, this requires detailed understanding of the field of taxation, and still suffers from a lack of published data on which to base calculations. It is apparent that the datasets exist; indeed, the Office for National Statistics passes data to the Scottish Executive to be used in producing final demand in basic prices for Scotland (Croasdale 2006). However, due to ONS regulations, which are designed to protect against release of disclosive information, the data are not made available.

We now consider how import and domestic supplied final demand can be separated from combined final demand. Data provided in the annual Supply and Use Tables includes total imports in the Supply Table. This column includes imports used for both intermediate demand to industry and to meet all elements of final demand. No indication is given, however, of the proportions that should be allocated to each of these. Various options exist for apportioning: one methodology is to assume that all elements of intermediate and final demand purchase an equal proportion of imports. Another option is to assume that all elements of intermediate and final demand purchase the same proportions of imports for the year in question as in 1995, and to apportion using the 1995 Imports Use Matrix as a basis. Again, both these methods give different results. In the current study we use the second of the methods described above, as this gave best results when tested for consistency with respect to carbon (this test is explained in Section 5).

\subsection{Representation of industry structure in years after 1995}

From Table 1 it will be seen that the last published UK Leontief Inverse Matrix is for 1995. Various options are available for representing industrial structure for years after 1995. In this paper we will consider four options, namely: using 1995 Leontief adapted from 138 to 123 sectors; updating the 1995 Leontief Inverse matrix; adapting a Leontief from a country with a similar industrial structure to the UK to represent the UK; and derivation of alternative total requirements matrix from the Supply and Use tables. Other methodologies are also possible but are not considered promising (Miller and Blair 1985; Israilevich et al. 1997; Jackson and Murray 2004).

The 1995 Leontief Inverse Matrix is, as stated above, in 138 sectors. However, all subsequent relevant monetary data are published in 123 sectors. The 123 and 138 sector matrices differ in their representation of government and Not for Profit Institutions Serving Households (NPISHs), both of which can be analysed as either producers or consumers. The 138 sector economy is based on the 123 sector economy, but with government and NPISH as final consumers separated out to form the "extra" sectors 124-138 (Office for National Statistics 2002). Therefore a 123 sector A-Matrix may be calculated from the 138 A-Matrix by amalgamating the "extra" sectors from whence they were separated. A 123 Leontief Inverse Matrix can subsequently be calculated.

We may attempt to reflect changes in the industrial structure since 1995 by applying the fairly standard procedure of "rolling" the A-Matrix forward using the RAS technique (Miller and Blair 1985; Israilevich et al. 1997). The RAS technique may also be used to adapt another country's A-Matrix to represent UK industry structure by making the assumption that modern economies contain similar patterns of inter-related industries (Simpson and Tsukui 
1965; Tukker et al. 2006). The RAS technique is a biproportional technique that enables an initial $n \times n$ A-matrix to be updated or balanced to produce a target matrix where the total industry outputs, total industry inputs and total intermediate outputs are specified (Jackson and Murray 2004). For example, in order to update the 1995 A-Matrix to 2004 using the RAS technique, the data required for the 2004 are: total output in basic prices $\mathbf{x}$; total inter-industry sales in basic prices $\mathbf{w}_{\mathbf{i}}$; and total inter-industry purchases in basic prices $\mathbf{v}_{\mathbf{i}}$, where

$$
\mathbf{w}_{\mathbf{i}}=\sum_{\mathrm{j}=1}^{\mathrm{n}} \mathbf{z}_{\mathrm{ij}}
$$

and

$$
\mathbf{v}_{\mathbf{i}}=\sum_{\mathrm{i}=1}^{\mathrm{n}} \mathbf{z}_{\mathrm{ij}}
$$

and $z_{i j}$ denotes sales from sector $\mathrm{i}$ to sector $\mathrm{j}$. The Supply and Use Tables provide us with $\mathbf{x}$. However, $\mathbf{w}_{\mathbf{i}}$, and $\mathbf{v}_{\mathbf{i}}$ are more problematic as the Use Table produced by the Office for National Statistics is in purchaser prices, and is not published in basic prices (see discussion above).

The advantages of the RAS technique are that it is relatively simple to carry out (Lahr and de Mesnard 2004), it assures that no negative values can be achieved (Miller and Blair 1985), and has been found to give superior accuracy to other alternative methodologies when all values in the matrices are positive (Jackson and Murray 2004). However, it has significant drawbacks. For example, it assumes that the A-matrix coefficients change uniformly along rows and columns, an assumption for which there is considered to be little economic justification (Pan 2004). It is also severely limited in its usefulness with regards to the UK due to lack of up-to-date Use Tables in basic prices.

The UK 1995 Leontief Inverse Matrix is a total requirements matrix representing the UK economy in product by product formation based on hybrid technology assumption (Office for National Statistics 2002). An alternative approach is to form a matrix of total requirements based on product by industry, industry by product, or industry by industry tables, by application of data from the Supply and Use Tables. This procedure is explained in detail in Miller and Blair (1985) and Wiedmann et al (2006). However, once again, we come up against the problem of requiring a Use Table in basic prices which, as discussed above, is not published by the ONS. Therefore we can conclude that, although this may seem a possible way forward, the data required are not yet routinely available.

In the interest of making progress and drawing attention to the issues of data availability, we have used the 1995 Leontief Inverse Matrix (adapted from 138 to 123 sectors as explained above) for the basis of calculating the results that follow. Although input-output coefficients are relatively stable over time (Carter 1970) and are only generally produced at five yearly intervals (European Commission 2007), the consequence of this choice is that changes in the structure of the UK economy between 1995 and 2004 are not captured in this study. The advantage of this choice is the robust, accredited status of the 1995 Leontief Inverse Matrix.

\section{A comparison of carbon attribution in 1990 and 2004}

According to the IPCC reporting, emissions from the production perspective have fallen from $161.5 \mathrm{mtC}$ in 1990 to $152.5 \mathrm{mtC}$ in $2004^{9}$. According to the production perspective used in this

$9 \quad$ See Defra E-Digest of Environmental Statistics, available from http://www.defra.gov.uk/environment/statistics/globatmos/gagccukmeas.htm downloaded 12.10.06. 
study, which is based on the UK Environmental Accounts, total carbon emissions rose very slightly from $174.0 \mathrm{mtC}$ in 1990 to $174.4 \mathrm{mtC}$ in 2004 . The difference between these two perspectives is explained by differences in the way in which the Environmental Accounts are presented from that used for the UNFCCC and the Kyoto Protocol. In particular, the Environmental Accounts include emissions due to international travel, including aviation and shipping, which are excluded from the UNFCCC statistics. A more comprehensive description of these differences is given in the Environmental Accounts (Office for National Statistics 2006: page 28), and a reconciliation between the two production-based accounts in this paper is shown in Table 2.

Turning our attention to the consumption perspective, we find an even more radical departure from the trend portrayed by the conventional (IPCC) account. In this case, the result of the EIO analysis based on the Environmental Accounts suggests that carbon emissions rose from $175.4 \mathrm{mtC}$ in 1990 to $189 \mathrm{mtC}$ in 2004.

Figure 2 illustrates clearly the difference that choice of reporting convention makes. According to IPCC reporting, emissions have fallen by 5.6\% from 1990 to 2004, whereas including the impacts of international travel using the Environmental Accounts reveals that emissions have increased very slightly $(0.3 \%)$ over the period. Most strikingly, when calculated according to the consumption perspective in this study, emissions are estimated to have increased by $8 \%$ between 1990 and 2004 .

We look now at what these figures mean for the carbon trade balance. In 1990 emissions according to the consumption perspective were $1.5 \mathrm{mtC}$ more than emissions by the production perspective (both based on the Environmental Accounts). This means that the UK had a carbon trade balance of $1 \%$ in 1990; in other words, the UK was exporting very slightly more carbon than it was importing. In 2004, emissions according to the consumption perspective were estimated to be $15 \mathrm{mtC}$ higher than those calculated under the production perspective, representing a carbon trade balance of $8 \%$.

This swing from a carbon trade balance of 1\% in 1990 to one of $8 \%$ in 2004 seems fairly consistent with results obtained by Proops et al (1993) who estimated that the UK carbon trade balance changed from $-5.7 \%$ in 1974 to $-3.2 \%$ in 1984 . These results for the UK may also be compared with those for Denmark, for which the trade balance was found to shift from $-7.4 \mathrm{mtC}$ in 1966 to $+6.9 \mathrm{mtC}$ in 1994 with the cross over from a negative to positive trade balance occurring from approximately 1982 to 1986 (Munksgaard and Pedersen 2001). The results suggest that the UK is increasingly exporting its more carbon intensive industries, as has been found for Denmark, and the findings support the pollution haven hypothesis discussed in Section 1.

The results described above are based on the assumption that imported goods have the same carbon footprint as those produced domestically (the 'domestic technology assumption'). Using this assumption, the carbon associated with flows of goods produced in the Rest of the World to meet intermediate and final demand $\left(C_{Q}\right.$ plus $\left.C_{R}\right)$ accounts for $19 \%$ of carbon emissions in 1990 and $23 \%$ in 2004 . However, as discussed above, the domestic technology assumption is likely to underestimate carbon emissions associated with imports, particularly those from developing countries. The proportion of imports from non-OECD countries was $15 \%$ in 1990 and $24 \%$ in 2004. A sensitivity analysis in which the carbon footprint of goods imported from non-OECD countries is assumed to be double that of domestically produced goods and goods imported from OECD countries has been carried out. Using these 
assumptions, estimates of carbon emissions from the consumption perspective rose to $182 \mathrm{mtC}$ in 1990 and $199 \mathrm{mtC}$ in 2004, giving carbon trade balances of $5 \%$ in 1990 and $14 \%$ in 2004. These results underline the importance of developing a full multi-regional inputoutput model for the UK. The other major source of errors, which is the subject of this paper, is the reliability of the underlying UK datasets, and this is explored in the next section.

\section{Robustness analysis}

As discussed in Section 3, published, accredited and up-to-date monetary data on which EIO depends are not available in the UK after 1995. In order to answer the question posed in this paper, it was necessary to employ a variety of estimations and manipulations using the best publicly available data we could find. In this section we ask the question, how robust are the results as a consequence of this? A simple way to assess the accuracy is to go back to the input-output relationship shown in equation (3). This states that total output (x) equals the Leontief Inverse matrix (I-A) $)^{-1}$ multiplied by final demand (y). A basic consistency check is to determine the percentage difference between the left and right hand sides of equation (3) as calculated using our estimated data. We refer to this difference as the 'monetary error'. The same principle can be applied to the carbon relationship described in equation (6), and we refer to this as the 'carbon error'. These consistency checks are, of course, not ideal measures of accuracy, as they give no indication of the source of the errors, whether they be in the final demand or the industrial coefficients matrix. Nevertheless, they provide a simple indicator on which to base our discussions of accuracy.

Application of these consistency tests for the UK domestic economy, including exports and excluding imports, show that for 1990, where a complete set of required data is published, the left and right-hand side match very closely (within 0.5\%). Similarly, for 1995 using 138 sector Leontief Inverse Matrix and final demand, with 123 sector total output, the left and right-hand sides match, or in other words, the data show a high level of consistency. Use of simply the top 123 sectors of the 138 sector Leontief Inverse Matrix would give a monetary error of $2.2 \%$, but the data shows both monetary and carbon consistency once the 138 Leontief Inverse Matrix is adjusted to 123 sectors as described in Section 3.2.

For 2004, the story is not so successful. Using final demand in basic prices calculated as outlined above (but including exports and excluding imports), and the 1995 Leontief Inverse Matrix adjusted to 123 sectors, yields errors of $7 \%$ for monetary consistency and $18 \%$ for carbon consistency.

By way of comparison, we carried out similar checks on the annual IO datasets produced by Statistics Finland. These attain monetary consistency (within $0.5 \%$ ) every year. The monetary consistency is not, however, entirely perfect and errors vary, ranging from $-0.29 \%$ in 2001 to $+0.04 \%$ in 1996 . In general, monetary consistency errors tend to be amplified when the model is applied to carbon. At the time of writing, data to calculate carbon consistency were not available for Finland, so we have been unable to carry out this check. However, the data for Finland undoubtedly form a more robust platform for carrying out consumption based accounting than those provided for the UK by the ONS for years after 1995.

As a result of these consistency tests we can have confidence in the results shown in Section 4 for 1990, but the results for 2004 must be treated with some caution. Admittedly, the consistency errors found for 2004 are not directly transferable to the results of the 
consumption perspective account for 2004 (reported in Section 4), because the consistency tests apply simply to the domestic Leontief inverse matrix rather than to the full suite of EIO equations. The lack of consistency in the basic Leontief equation does, however, suggest that the model may be over-estimating results, biasing the model towards producing a higher positive trade balance.

It is important to note here that all UK studies concerned with years after 1995 face the same challenges as this paper. This includes, for example the REAP ${ }^{10}$ model as described in Wiedmann et al (2006) and WWF-UK (2006), the Office for National Statistics' report on the impact of UK households on the environment (Francis 2004), as well as previous work on which the study reported here is based (Jackson et al 2006, Carbon Trust 2006). As a result other similar studies for the UK are not considered a useful benchmark for the results derived here. So for guidance on the credibility of our results with respect to total UK carbon emissions from the consumption perspective in 2004 we return to the findings calculated by Proops et al in their study of the UK from 1968 to 1984 (Proops et al. 1993), and those for Denmark from 1966 to 1994 (Munksgaard and Pedersen 2001). As discussed in Section 4, the general trend of an increase in carbon emissions from the consumption perspective and increase in carbon trade balance with time appear to be in line with these studies. However, questions must remain concerning the size of the increase over time derived here.

\section{Conclusion}

In this paper we have shown that the accounting convention chosen for reporting carbon emissions radically changes the conclusions that may be drawn about UK's progress towards its carbon reduction targets. According to the UNFCCC reporting convention, carbon emissions fell by 5.6\% between 1990 (the Kyoto base year) and 2004. If we base our calculations on figures produced in the UK Environmental Accounts, which additionally account for aviation and shipping emissions (excluded from the UNFCCC convention), the picture is less clear. In fact, on this basis, progress towards the Kyoto target appears to be almost wiped out, with carbon emissions having risen by $0.3 \%$ over the time period. More significantly, when emissions are estimated according to the consumption perspective, (which we take to be the more appropriate approach), we find that emissions have risen by $8 \%$ over the same time span. We also find that the UK's carbon trade balance has risen from $1 \%$ in 1990 to $8 \%$ in 2004 .

The estimates of emissions from the consumption perspective have severe policy implications and are a cause for deep concern, therefore the question of their robustness is of prime importance. We have shown in this paper that there are two major sources of errors and conclude, ultimately, that confidence in the estimated total carbon dioxide emissions according to the consumption perspective, particularly in 2004, is low. The first source of uncertainty is the domestic technology assumption, which causes underestimates of the carbon trade balance: this uncertainty will be addressed by developing a multi-region inputoutput model. The second source of uncertainties is caused by lack of published economic datasets in the UK, and is the subject of this paper.

The source of our problems in estimating emissions for years after 1995 is that the UK Office for National Statistics has not published the economic datasets on which Environmental Input-Output modelling are based. Worryingly, there are no explicit plans to produce the datasets before 2010, despite a legal obligation on the UK to do so as an EU member state. In

\footnotetext{
${ }^{10}$ Resources and Energy Analysis Programme, see http://www.sei.se/reap/index.php.
} 
contrast to the situation in the UK, other countries such as Finland produce these data annually and when tested these data pass basic consistency tests. The importance of consumption based accounting is appreciated by some parts of the UK government. For example, within the Department for Environment, Food and Rural Affairs (Defra), the Sustainable Consumption and Production Evidence Base team has a commitment to produce an 'embedded' carbon emissions indicator. But in the absence of robust, up-to-date monetary datasets on which to build Environmental Input-Output analysis, we cannot currently have confidence in the estimates for consumption-based accounts for years after 1995.

There is an urgent policy need to address this situation. Without robust, verifiable, consistent underlying data, the question which motivated this paper simply cannot be answered with any reasonable degree of confidence, and we remain unable to measure real progress towards meaningful carbon reduction in the UK.

\section{Acknowledgements}

The authors would like to thank Sanjiv Mahajan for his advice and three anonymous referees for their very constructive comments and suggestions. This research was made possible through funding from the ESRC Research Group on Lifestyles Values and Environment (RESOLVE) (Grant Number RES-152-25-1004), and from the EPSRC Sustainable Urban Environment Waste Consortium programme (Grant Number GR/S79626/01). 


\section{References}

Ahmad, N. and A. Wyckoff, 2003. Carbon dioxide emissions embodied in international trade of goods. Paris, France, OECD.

Bastianoni, S., F. M. Pulselli and E. Tiezzi, 2004. "The problem of assigning responsibility for greenhouse gas emissions." Ecological Economics 49(3): 253-257.

Carbon Trust, 2006. The carbon emissions generated in all that we consume. London, UK, Carbon Trust.

Carter, A., 1970. Structural Change in the American Economy, Harvard University Press, Cambridge, Massachusetts, USA.

Croasdale, S., 2006. Personal communication between Stevan Croasdale (Scottish Executive) and Pete Bradley (University of Surrey) 28.11.06 and 04.04.07.

Department of Trade and Industry. 2006. "Digest of United Kingdom Energy Statistics (DUKES)." The Stationery Office, London, UK, Accessed 19.03.06, from http://www.dti.gov.uk/energy/statistics/publications/dukes/page29812.html.

ENDS. 2007. "UK plans to put 60 per cent carbon cut in law." Accessed 17.03.07, from http://www.endseuropedaily.com/articles/index.cfm.

European Commission. 2007. "ESA 95 Input-Output tables." Accessed 02.04.07, from http://epp.eurostat.ec.europa.eu/portal/page?_pageid=2474,54156821,2474_54764840 $\underline{\&}$ dad $=$ portal \& schema $=$ PORTAL.

Femia, A. and S. Moll, 2005. Use of MFA-related tools in environmental policy-making. Copenhagen, Denmark, European Environment Agency. P3.1-2004.

Francis, P., 2004. The impact of UK households on the environment through direct and indirect generation of greenhouse gases. London, UK, Office for National Statistics.

HM Government, 2007. Draft Climate Change Bill. London, UK, TSO.

International Energy Agency, 2006. CO2 Emissions from Fuel Combustion 1971-2004. Paris, France, OECD.

Israilevich, P. R., G. J. D. Hewings, M. Sonis and G. R. Schindler, 1997. "Forecasting Structural Change With a Regional Econometric Input-Output Model." Journal of Regional Science 37(4): 565-590.

Jackson, R. W. and A. T. Murray, 2004. "Alternative Input-Output Matrix Updating Formulations." Economic Systems Research 16(2).

Jackson, T., E. Papathanasopoulou, P. Bradley and A. Druckman, 2006. Attributing Carbon Emissions to Functional Household Needs: a pilot framework for the UK. International Conference on Regional and Urban Modelling, Brussels, Belgium. 1-2 June 2006. 
Jackson, T., E. Papathanasopoulou, P. Bradley and A. Druckman, 2007. Attributing UK Carbon Emissions to Functional Consumer Needs: methodology and pilot results. RESOLVE Working Paper 0601, University of Surrey.

Lahr, M. L. and L. de Mesnard, 2004. "Biproportional Techniques in Input-Output Analysis: Table Updating and Structural Analysis." Economic Systems Research 16(2): 115134.

Lenzen, M., 2001. "Errors in Conventional and Input-Output-based Life-Cycle Inventories." Journal of Industrial Ecology 4(4): 127.

Lenzen, M., L. Pade and J. Munksgaard, 2004. "CO 2 Multipliers in Multi-region InputOutput Models." Economic Systems Research 16(4): 391.

Leontief, W., 1986. Input-output economics. 2nd Edition. New York, USA, Oxford University Press.

Machado, G., R. Schaeffer and E. Worrell, 2001. "Energy and carbon embodied in the international trade of Brazil: an input-output approach." Ecological Economics 39(3): 409-424.

Mahajan, S., 2007. UK National Accounts: GDP and Input-Output Supply and Use Tables. 16th International Input-Output Conference, Istanbul, Turkey, 2-6 July 2007.

McGregor, P. G., J. K. Swales and K. R. Turner, 2004. The Environmental 'Trade Balance' Between Scotland and the Rest of the UK: An Inter-Regional Input-Output and SAM Analysis, Discussion Paper in Economics (04-21). University of Strathclyde, Glasgow, UK.

Miller, R. E. and P. D. Blair, 1985. Input-output analysis: foundations and extensions. Englewood Cliffs, New Jersey, USA., Prentice-Hall.

Munksgaard, J. and K. A. Pedersen, 2001. "CO2 accounts for open economies: producer or consumer responsibility?" Energy Policy 29(4): 327-334.

Nijdam, D. S., H. C. Wilting, M. J. Goedkoop and J. Madsen, 2005. "Environmental Load from Dutch Private Consumption: How Much Damage Takes Place Abroad?" Journal of Industrial Ecology 9(1-2): 147.

Office for National Statistics. 2002. "United Kingdom Input-Output Analytical Tables, 1995." Accessed 12.03.07, from http://www.statistics.gov.uk/statbase/Product.asp?vlnk=497.

Office for National Statistics, 2003. United Kingdom National Accounts. The Blue Book 2003. TSO, London, UK.

Office for National Statistics. 2006. "Environmental Accounts." Accessed 02.03.07, from http://www.statistics.gov.uk/statbase/Product.asp?vlnk=3698. 
Office for National Statistics. 2007. "United Kingdom Balance of Payments - The Pink Book." Accessed 21.10.07, from http://www.statistics.gov.uk/StatBase/Product.asp?vlnk=1140.

Pan, H., 2004. The evolution of economic structure under technological development, Tyndall Centre for Climate Change Research; Working Paper 48.

Papathanasopoulou, E. and T. Jackson, 2007. "Fossil Resource Trade Balances: emerging trends for the UK." Jounal of Industrial Ecology Accepted for publication.

Peters, G. and E. Hertwich, 2006. "The Importance of Imports for Household Environmental Impacts." Journal of Industrial Ecology 10(3): 89-109.

Proops, J. L. R., M. Faber and G. Wagenhals, 1993. Reducing CO2 Emissions. A Comparative Input-Output Study for Germany and the UK. Berlin, Germany, Springer-Verlag.

Rypdal, K. and W. Winiwarter, 2001. "Uncertainties in greenhouse gas emission inventories evaluation, comparability and implications." Environmental Science \& Policy 4(2-3): 107.

Simpson, D. and J. Tsukui, 1965. "Structure of Input-Output Tables." The Review of Economics and Statistics: 434-446.

Tukker, A. and B. Jansen, 2006. "Environmental Impacts of Products: A Detailed Review of Studies." Journal of Industrial Ecology 10(3): 159.

Tukker, A., P. Eder and S. Suh, 2006. "Environmental Impacts of Products: Policy Relevant Information and Data Challenges." Journal of Industrial Ecology 10(3): 183.

United Nations, 2004. Guidelines for the preparation of national communications by Parties included in Annex I to the Convention, Part I: UNFCCC reporting guidelines on annual inventories (following incorporation of the provisions of decision 13/CP.9). Buenos Aires, Argentina. 6-14 December 2004, Subsidiary Body For Scientific And Technological Advice. Twenty-first session.

Weber, C. L. and H. S. Matthews, 2007. "Embodied Environmental Emissions in U.S. International Trade, 1997-2004." Environ. Sci. Technol. 41(14): 4875-4881.

Wiedmann, T., J. Minx, J. Barrett and M. Wackernagel, 2006. "Allocating ecological footprints to final consumption categories with input-output analysis." Ecological Economics 56(1): 28-48.

Wiedmann, T., M. Lenzen, K. Turner and J. Barrett, 2007. "Examining the global environmental impact of regional consumption activities - Part 2: Review of inputoutput models for the assessment of environmental impacts embodied in trade." Ecological Economics 61(1): 15. 
Wilting, H. C. and K. Vringer, 2007. Environmental Accounting from a Producer or a Consumer Principle: an Empirical Examination covering the World. 16th International Input-Output Conference, Istanbul. Turkey, 2-6 July 2007.

WWF-UK, 2006. Counting Consumption: CO2 emissions, material flows and Ecological Footprint of the UK by region and devolved country. WWF-UK, Godalming, Surrey, UK.

Table 1. Publication of monetary data required for Environmental Input-Output Analysis for UK, Scotland and Finland

\begin{tabular}{|c|c|c|c|c|}
\hline \multirow[b]{2}{*}{ Data Required } & \multirow[b]{2}{*}{$\begin{array}{l}\text { Price } \\
\text { basis } \\
\text { required }\end{array}$} & \multicolumn{3}{|c|}{ Publication of required data } \\
\hline & & UK & Scotland & Finland \\
\hline Leontief Inverse Matrix $(I-A)^{-1}$ & & $\begin{array}{l}1990 \text { (123 sectors) } \\
1995 \text { (138 sectors) }\end{array}$ & $\begin{array}{l}\text { Annual 1998-2003 } \\
\text { (127 sectors) }\end{array}$ & $\begin{array}{l}\text { Annual since } 1995 \\
\text { (93 sectors) }\end{array}$ \\
\hline Imports Use Matrix $B_{21}$ & & $\begin{array}{l}1990 \text { (123 sectors) } \\
1995 \text { (138 sectors) }\end{array}$ & Not available & $\begin{array}{c}\text { Annual since } 1995 \\
\text { (93 sectors) }\end{array}$ \\
\hline Total Output $x$ & Basic & Annual (123 sectors) & $\begin{array}{l}\text { Annual 1998-2003 } \\
\text { (127 sectors) }\end{array}$ & $\begin{array}{c}\text { Annual since } 1995 \\
\text { (93 sectors) }\end{array}$ \\
\hline $\begin{array}{l}\text { Final demand - domestic } \\
\text { supplied } y^{11}\end{array}$ & Basic & $\begin{array}{l}1990 \text { (123 sectors) } \\
1995 \text { (138 sectors) }\end{array}$ & $\begin{array}{l}\text { Annual } 1998-2003 \\
\text { (127 sectors) }\end{array}$ & $\begin{array}{l}\text { Annual since } 1995 \\
\text { (93 sectors) }\end{array}$ \\
\hline Final demand - imported $y^{21}$ & Basic & $\begin{array}{l}1990 \text { (123 sectors) } \\
1995 \text { (138 sectors) }\end{array}$ & Not available & $\begin{array}{l}\text { Annual since } 1995 \\
\text { (93 sectors) }\end{array}$ \\
\hline
\end{tabular}


Table 2 - Reconciliation of Production Perspective Accounts

\begin{tabular}{|c|c|c|}
\hline Carbon Emissions from the Production Perspective & $\begin{array}{l}1990 \\
(\mathrm{mtC})\end{array}$ & $\begin{array}{r}2004 \\
(\mathrm{mtC})\end{array}$ \\
\hline $\begin{array}{l}\text { This study - based on Fuel Use by Industry as published by ONS in } \\
\text { the Environmental Accounts }{ }^{11}\end{array}$ & 174.0 & 174.4 \\
\hline $\begin{array}{l}\text { Adjustments: } \\
\text { Fuels omitted (eg biomass) (+) } \\
\text { Adjustment due to double counting to account for auto-generation }{ }^{12}(-)\end{array}$ & -3.0 & -1.5 \\
\hline Total carbon based on Environmental Accounts - published figure & 171.0 & 172.9 \\
\hline Adjustments as in Bridging Table $e^{13}$ & & \\
\hline Cross-boundary (-) & 3.4 & 6.8 \\
\hline Bunker emissions (-) & 6.1 & 10.6 \\
\hline CO2 biomass (-) & 0.8 & 2.6 \\
\hline Overseas Territories (+) & 0.3 & 0.3 \\
\hline Additional Sectors (under UNECE) (+) & 0.4 & 0.3 \\
\hline UNECE reported figure $\mathrm{e}^{14}$ & 161.4 & 153.6 \\
\hline IPCC reported figure ${ }^{15}$ & 161.5 & 152.5 \\
\hline
\end{tabular}

Source: adapted from Office for National Statistics (2006).

\footnotetext{
${ }^{11}$ See Office for National Statistics (2005). Environmental Accounts: Carbon fuel use by 93 industries. http://www.statistics.gov.uk/statbase/Product.asp?vlnk=7166\&More=Y

${ }^{12}$ See Digest of United Kingdom Energy Statistics (DUKES) (Department of Trade and Industry 2006). http://www.dti.gov.uk/energy/statistics/publications/dukes/page29812.html

${ }^{13}$ See Bridging Table published in Environmental Accounts Table D8249 downloaded 23.03.07 from http://www.statistics.gov.uk/statbase/Expodata/Spreadsheets/D8249.xls

${ }^{14}$ See Bridging Table published in Environmental Accounts Table D8249 downloaded 23.03.07 from http://www.statistics.gov.uk/statbase/Expodata/Spreadsheets/D8249.xls

${ }^{15}$ The IPCC reported figure differs slightly from the UNECE figure in terms of the coverage of land use change and soil emissions. See Defra e-Digest Statistics about: Global Atmosphere, accessed 23.03.07, from http://www.defra.gov.uk/environment/statistics/globatmos/gagccukmeas.htm\#gatb2.
} 
Figure 1

A Two-Region Carbon Attribution Model

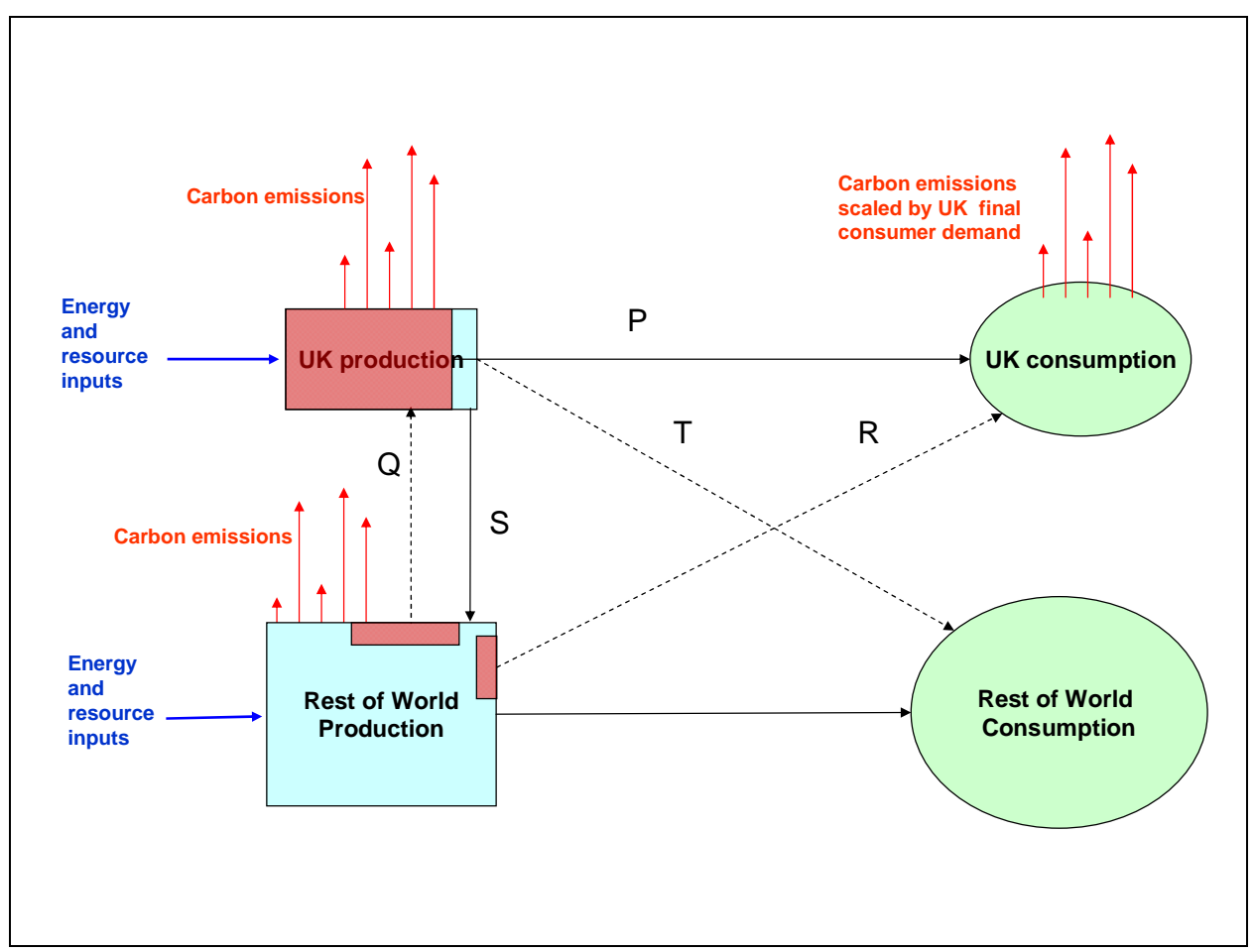


Figure 2. UK carbon accounts for 1990 and 2004 from different accounting perspectives

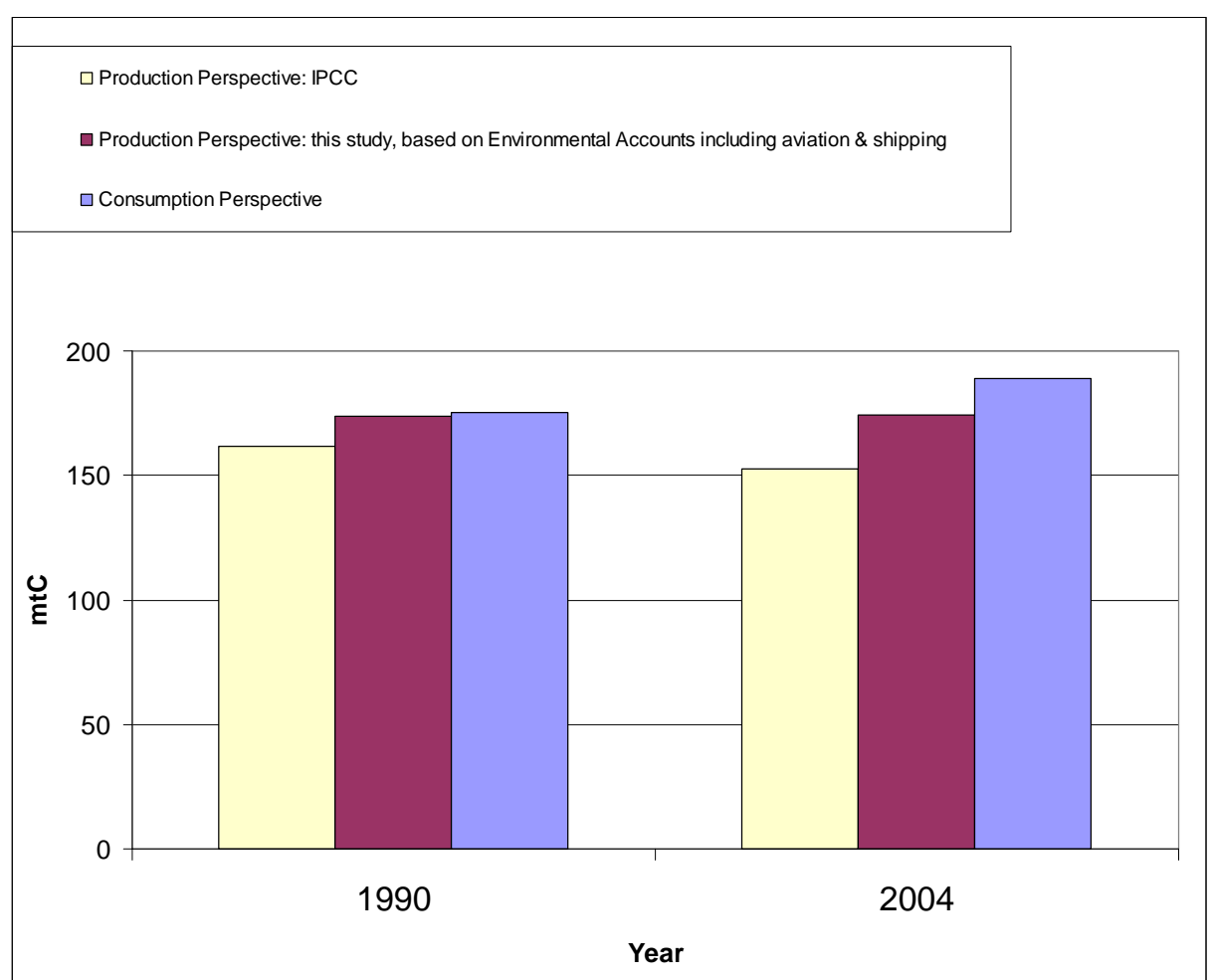

